\title{
Prognostic value of clinical and morphologic findings in patients with type $B$ aortic intramural hematoma
}

\author{
Zilun $\mathrm{Li}^{1,2,3 \dagger}$, Chenshu Liu' ${ }^{1,2,3+}$, Ridong $\mathrm{Wu}^{1,2,3}$, Jian Zhang ${ }^{4}$, Hong Pan ${ }^{5}$, Jinghong Tan ${ }^{5}$, Zhuang Guo ${ }^{5}$, \\ Yingying Guo ${ }^{5}$, Nan Yu' ${ }^{1}$, Chen Yao ${ }^{1,2,3}$ and Guangqi Chang ${ }^{1,2,3^{*}}$
}

\begin{abstract}
Background: Aortic intramural hematoma $(\mathrm{IMH})$ is a subset of acute aortic syndrome, and its prognosis may differ between races. This study aimed to study the prognosis of Chinese type BIMH patients and to find out risk factors.

Methods: A total of 71 type B IMH patients with or without penetrating atherosclerosis ulcer (PAU) administrated in our center between September 2013 and October 2017 were retrospectively studied. Both clinical and imaging data were collected and analyzed. The primary end point was aorta-related death, and the secondary end point was progression, which was defined as enlargement of aorta, increased aortic wall thickness, and aortic dissection or aneurysm formation. Kaplan-Meier survival analysis and Cox regression analysis were used for prognostic analysis.

Results: Among these 71 patients, 21 had simple type BIMH, when 50 had type B IMH in association with PAU. Twenty-five patients received optimal medical therapy (OMT) alone, while 46 patients received surgery and OMT. The mean follow-up time was $27.5 \pm 13.5$ months. For type B IMH patients, association with PAU indicated poor prognosis and required more intensive management ( $H R=16.68,1.96 \sim 141.87)$, while maximum aortic diameter (MAD) was an independent risk factor ( $H R=1.096,1.016 ~ 1.182)$. For patients with PAU-IMH, MAD was an independent risk factor ( $H R=1.04,1.021 \sim 1.194)$, while surgical treatment was independent protective factor $(H R=0.172,0.042 \sim 0.696)$.

Conclusion: Association with PAU and MAD were independent risk factors for type B IMH patients. Surgery may improve the outcomes for type B IMH in association with PAU.
\end{abstract}

Keywords: Aortic intramural hematoma, Penetrating atherosclerosis ulcer, Chinese population

\section{Background}

Aortic intramural hematoma (IMH) is a subset of acute aortic syndrome (AAS), and is defined as crescentic or circumferential thickening of the aortic wall without any entry point by imaging techniques $[1,2]$. The epidemiology of IMH varies among different regions worldwide. $31.7 \%$ of patients were diagnosed as IMH relative to typical aortic dissection in Japan/Korea population, compared with $10.9 \%$ in North America (NA) /Europe.

\footnotetext{
* Correspondence: changgq@mail.sysu.edu.cn

†Zilun Li and Chenshu Liu contributed equally to this work.

'Division of Vascular Surgery, the First Affiliated Hospital of Sun Yat-sen University, Guangzhou, China

${ }^{2}$ National-Guangdong Joint Engineering Laboratory for Diagnosis and Treatment of Vascular Diseases, the First Affiliated Hospital of Sun Yat-sen University, Guangzhou, China

Full list of author information is available at the end of the article
}

This difference might be partially due the diagnosis criteria in different countries. Of note, significant difference of mortality rate between NA/Europe and Japan/Korea was also observed [3]. These differences suggest that the morbidity and mortality of IMH may be associated with race. Yet, studies from mainland China are scarce. Thus, this study aimed to demonstrate characteristics of Chinese patients with type B $\mathrm{IMH}$, and to find out prognostic factors based on our single center experience.

\section{Methods \\ Patients \\ From September 2013 to October 2017, 71 consecutive type B IMH patients administered or referral to our cen- ter were retrospectively studied. Type B IMH associated}


with penetrating atherosclerotic ulcer (PAU) was not excluded. Clinical data including demographic characteristics and potential prognostic factors were extracted.

\section{Imaging techniques}

Computed tomography angiography (CTA) was performed for all patients within $24 \mathrm{~h}$ after administration. IMH was defined as crescentic or circumferential thickening of the aortic wall $(>5 \mathrm{~mm})$ without any intimal tear, comparing with aortic dissection (AD). PAU was considered as a focal disruption in the arterial intima and elastic lamina protruding into the media [4], whereas IMH associated with PAU was termed as PAUIMH. Further differential diagnosis between PAU-IMH and rupture secondary to IMH was made with the presence or absence of intimal calcification [5] (Fig. 1). Maximum diameter of aorta and maximum thickening were measured, and PAU was recorded [6-8]. All CTA data were independently reviewed by two physicians, and discrepancy was settled with discussion.

Table 1 Patients' Basic Characteristics

\begin{tabular}{llll}
\hline Category & $\mathrm{IMH}(n=21)$ & $\mathrm{PAU}-\mathrm{IMH}(n=50)$ & $P$ value \\
\hline Background & & & \\
Age, y (mean \pm SD) & $56.3 \pm 11.4$ & $65.2 \pm 9.2$ & $<0.001$ \\
Male/Female & $18 / 3$ & $42 / 8$ & $>0.99$ \\
Smoking, n(\%) & $11(52.4 \%)$ & $27(54.0 \%)$ & 0.901 \\
Hypertension & $12(57.1 \%)$ & $26(52.0 \%)$ & 0.692 \\
Coronary heart disease & 0 & $5(10.0 \%)$ & 0.312 \\
Congenital heart disease & $1(4.8 \%)$ & $2(4 \%)$ & $>0.99$ \\
Diabetes & $1(4.8 \%)$ & $8(16.0 \%)$ & 0.194 \\
Hyperlipemia & $1(4.8 \%)$ & $1(2 \%)$ & 0.507 \\
Pregnancy & 0 & $1(2 \%)$ & $>0.99$ \\
History & & & 0.605 \\
History of AoD & $2(9.5 \%)$ & $7(14 \%)$ & 0.170 \\
History of any surgery & 0 & $6(12 \%)$ & \\
\hline a & & &
\end{tabular}
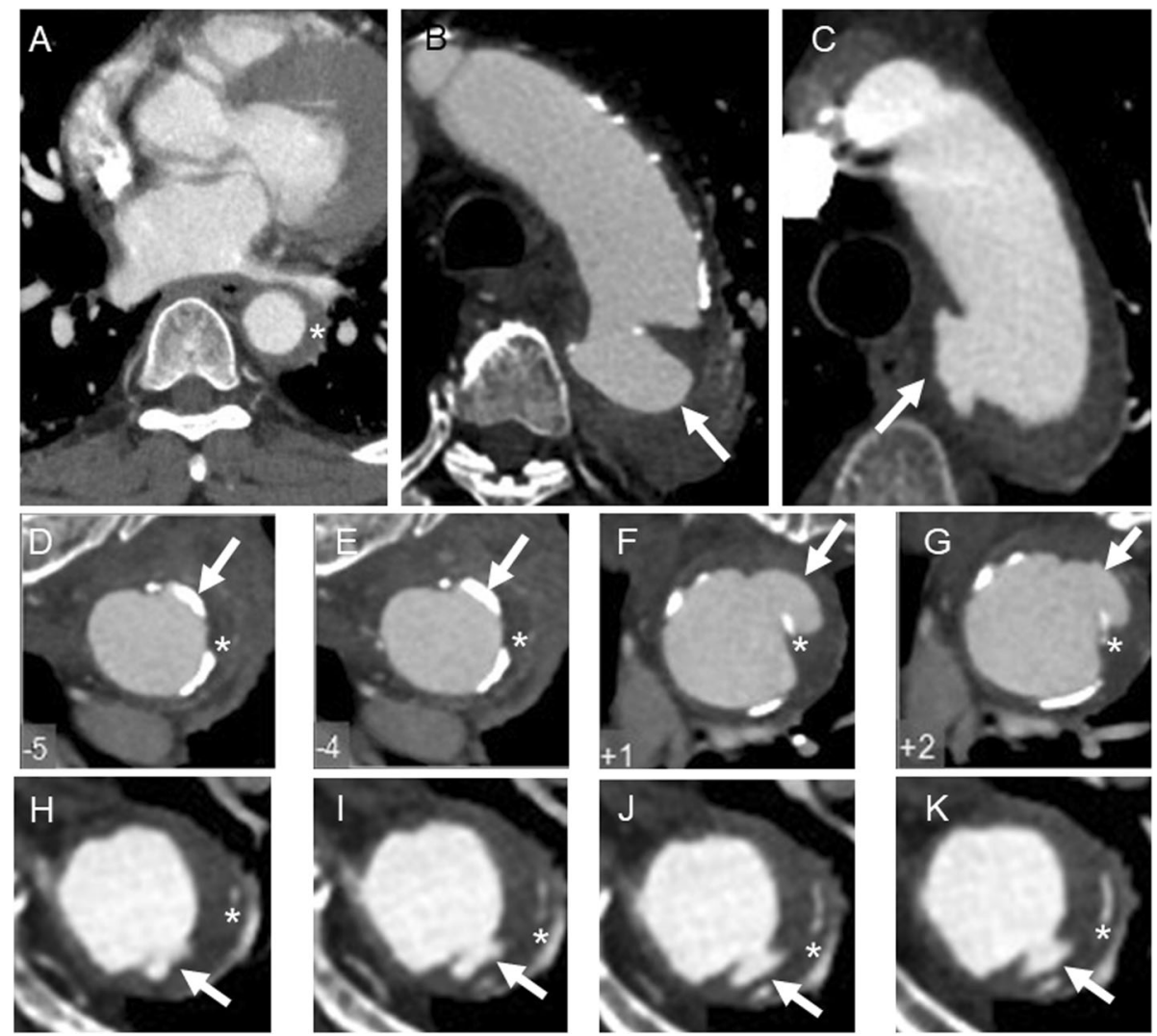

Fig. 1 a Typical intramural hematoma was defined as crescentic or circumferential uniform thickening of the aortic wall (>5 mm) without any intimal tear (Asterisk indicated). b \& c Penetrating ulcer was defined as a focal disruption in the arterial intima (Arrow indicated). $\mathbf{d}$ - $\mathbf{g}$ For differentiation of PAU and dissection, the calcification of intima was used as auxiliary line to locate the intima. As shown in $\mathbf{d}$ and $\mathbf{e}$, the frontier of projection (Arrow indicated) was calcified intima (Asterisk indicated), which protruded into the media on the following cross sections (f and $\mathbf{g}$ ). $\mathbf{h}-\mathbf{k}$ The projection (Arrow indicated) was located inside the calcified intima (Asterisk indicated), which is considered as rupture secondary to type B IMH 


\section{Management}

Optimal medical therapy (OMT) consisted of betablockers and/or other antihypertensive drugs. Patients with type B IMH only, stable hemodynamic and no indication for open surgery were referred to OMT and reexamination of CTA was performed 2 weeks later for further evaluation $[9,10]$. For PAU-IMH, surgery was considered if the ulcer had a width $>15 \mathrm{~mm}$ or depth $>10 \mathrm{~mm}$, or other indications $[11,12]$.

\section{Follow-up protocol}

Phone call follow-up was conducted quarterly, while CTA was performed at 6 months, 12 months and yearly thereafter. Within a mean follow-up of $26.5 \pm 13.0$ months, 7 patients $(9.8 \%)$ were lost. All patients received at least 2 CTA studies during follow-up. The primary endpoint was aorta-related death, and the secondary endpoint was progression, which was defined as enlargement of aorta $>5$ $\mathrm{mm}$, increased aortic wall thickness $>5 \mathrm{~mm}$, and AD or aneurysm formation during follow-up [13].

\section{Statistical analysis}

Continuous values are expressed as mean $\pm \mathrm{SD}$ and $t$ test was used for comparison. Categorical variables were expressed as frequencies and percentages and were compared with $\chi 2$ or Fisher's exact-test. Survival curves were generated via the Kaplan-Meier method with significant differences assessed for time-to-event data using logrank tests. Cox regression models were constructed to identify factors associated with prognosis and survival rates. $P$ value $<0.05$ was considered significant. The
Table 2 Initial Symptoms

\begin{tabular}{llll}
\hline Category & $\mathrm{IMH}(n=21)$ & $\mathrm{PAU}-\mathrm{IMH}(n=50)$ & $P$ value \\
\hline Associate pain, $\mathrm{n}(\%)$ & & & \\
Chest pain & $14(66.7 \%)$ & $24(48 \%)$ & 0.196 \\
Abdominal pain & $4(19 \%)$ & $12(24 \%)$ & 0.649 \\
Back pain & $12(57.1 \%)$ & $26(52 \%)$ & 0.692 \\
Waist pain & $4(19 \%)$ & $9(18 \%)$ & $>0.99$ \\
None & 0 & $13(26 \%)$ & 0.007 \\
Chest distress & $4(19.0 \%)$ & $4(8.0 \%)$ & 0.179 \\
Aortic regurgitation & 0 & 0 & \\
Pericardial effusion & $1(1.4 \%)$ & 0 & 0.296 \\
Myocardial ischemia & $1(1.4 \%)$ & $4(8.0 \%)$ & $>0.99$ \\
Dyspnea & $2(9.5 \%)$ & $4(8.0 \%)$ & $>0.99$ \\
Spinal cord ischemia & $1(4.8 \%)$ & $1(2.0 \%)$ & 0.507 \\
Syncope & 0 & $1(2.0 \%)$ & $>0.99$ \\
Hemothorax & 0 & $1(2.0 \%)$ & $>0.99$ \\
No symptom & 0 & $7(14.0 \%)$ & 0.096 \\
\hline
\end{tabular}

analyses were performed using SPSS version 24.0 (IBM SPSS, Chicago, Illinois).

\section{Results}

\section{Patient characteristics}

Among the 71 patients, 21 had simple type B IMH, while 50 had PAU-IMH (30\% vs. $70 \%$, Table 1). The mean age of 71 patients was $62.6 \pm 10.6$, and dominantly 60 of them $(84.5 \%)$ were male. Patients with type B PAU-IMH were significantly older than those with

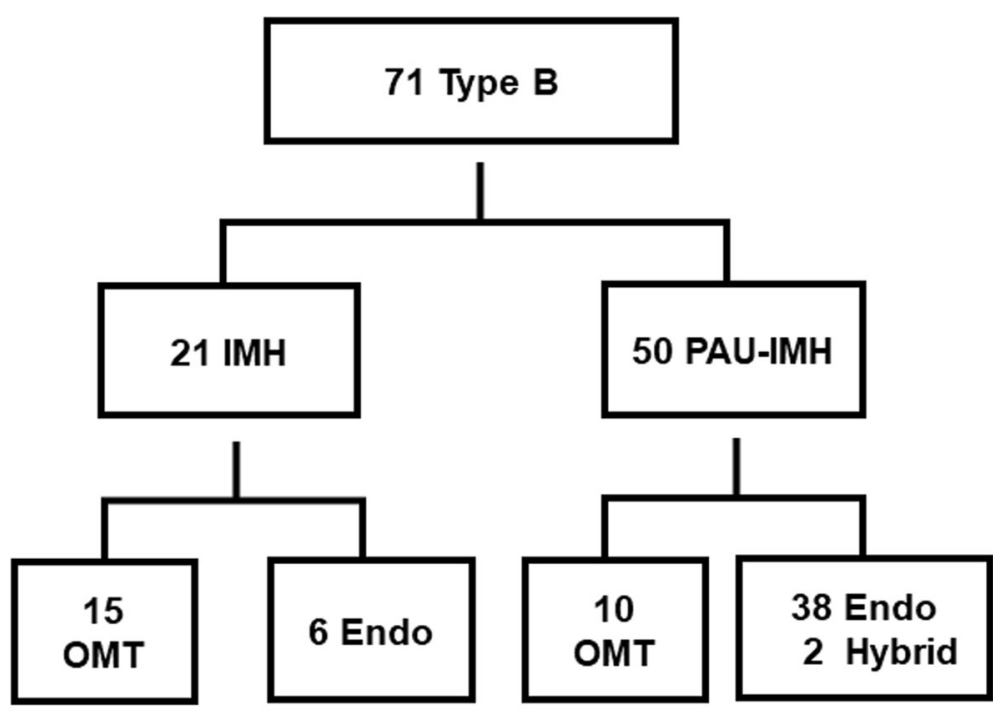

OMT: Optimal Medical Therapy

Endo: Endovascular Repair

Fig. 2 Flowchart of patients' treatment 
simple type B IMH $(65.2 \pm 9.2$ vs. $56.3 \pm 11.4, P<0.001)$. Hypertension (54\%) and smoking (54\%) were the most common risk factor, followed by diabetes mellitus (13\%), hyperlipemia (3\%). Coronary (7\%) and congenital (4\%) heart disease were also observed in both groups. Connective tissue diseases such as Marfan syndrome were not observed (data not shown). For all patients, 9 patients had a history of aortic disease (1 AD, 8 Aortic Aneurysm), whereas 6 patients had a history of surgery (1 open repair for AA, 2 endovascular repair for AA, 1 endovascular repair for $\mathrm{AD}$, and 2 others). No significant difference of history was observed between the two groups.

\section{Initial symptoms and comorbidities}

As shown in Table 2, the most common symptom was chest pain (54\%) and back pain (54\%), which was followed by abdominal pain (23\%). Chest distress (11\%), dyspnea (8\%), syncope (1\%) and hemothorax (1\%) were also observed. Among all the initial symptoms, more type B PAU-IMH patients showed no initial relevant pain during administration ( $26 \%$ vs. $0, P=0.007)$. In these 13 pain free patients, 3 had chest distress as initial symptom, 1 had syncope, 1 had spinal cord ischemia, while the remaining 8 had no symptoms.

\section{Treatment}

Among all the 71 type B IMH patients, 21 had simple type B IMH, while 50 had type B PAU-IMH (Fig. 2). In 50 patients with type B PAU-IMH, 38 patients received endovascular repair, and 2 underwent hybrid surgery, considering that the ulcer had a width $>15 \mathrm{~mm}$ or depth $>10 \mathrm{~mm}$ or other indications [11, 12]. For simple type B IMH, 6 patients received endovascular repair for refractory pain in 3, progression to aortic dissection in 2 and aneurysm in 1 , while the rest were managed with OMT.

\section{Survival analysis of different treatments for all patients}

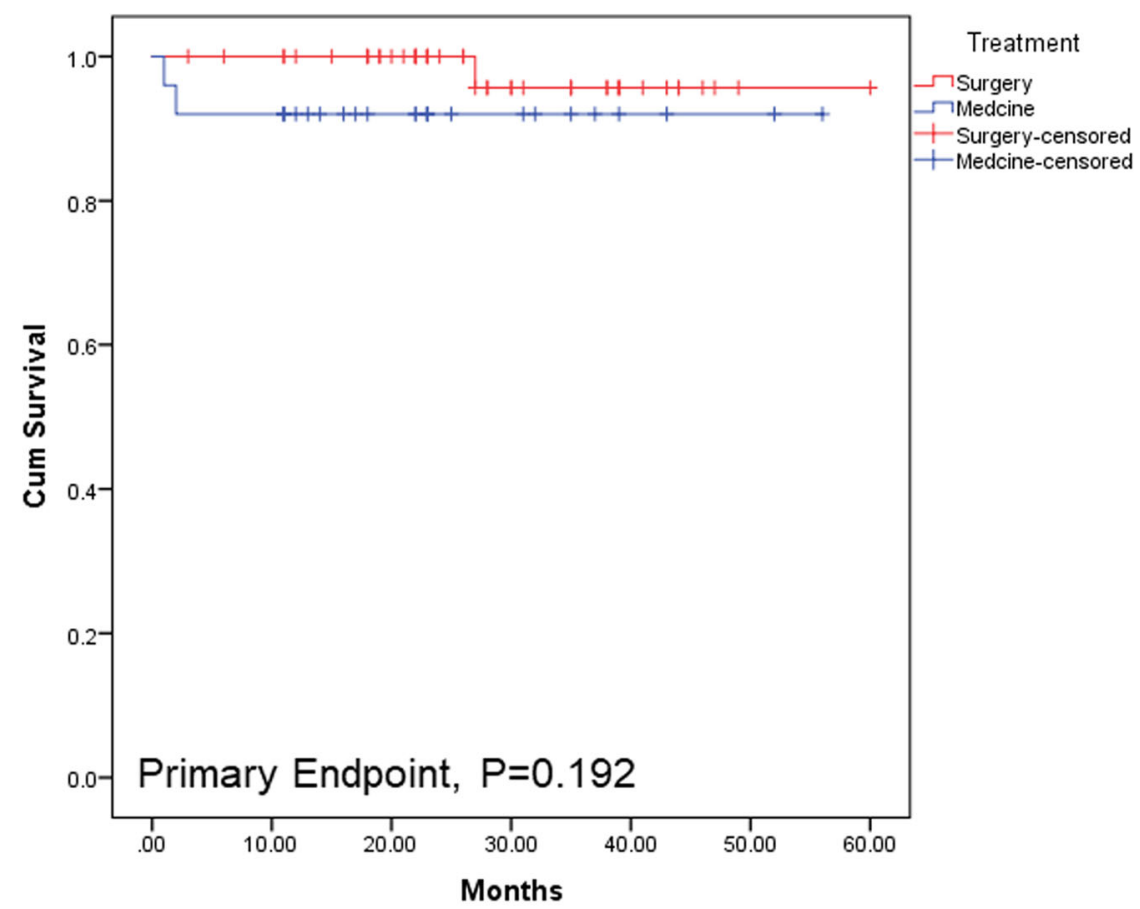

No. at Risk

\begin{tabular}{llllllll} 
Surgery & 46 & 45 & 30 & 10 & 4 & 3 & 1 \\
OMT & 25 & 24 & 20 & 17 & 11 & 2 & 1 \\
\multicolumn{7}{c}{ OMT: Optimal medical therapy }
\end{tabular}

Fig. 3 Kaplan-Meier survival curve for all type B IMH patients, surgery vs optimal medical therapy (OMT) 


\section{Survival analysis of different treatments for type B PAU-IMH}

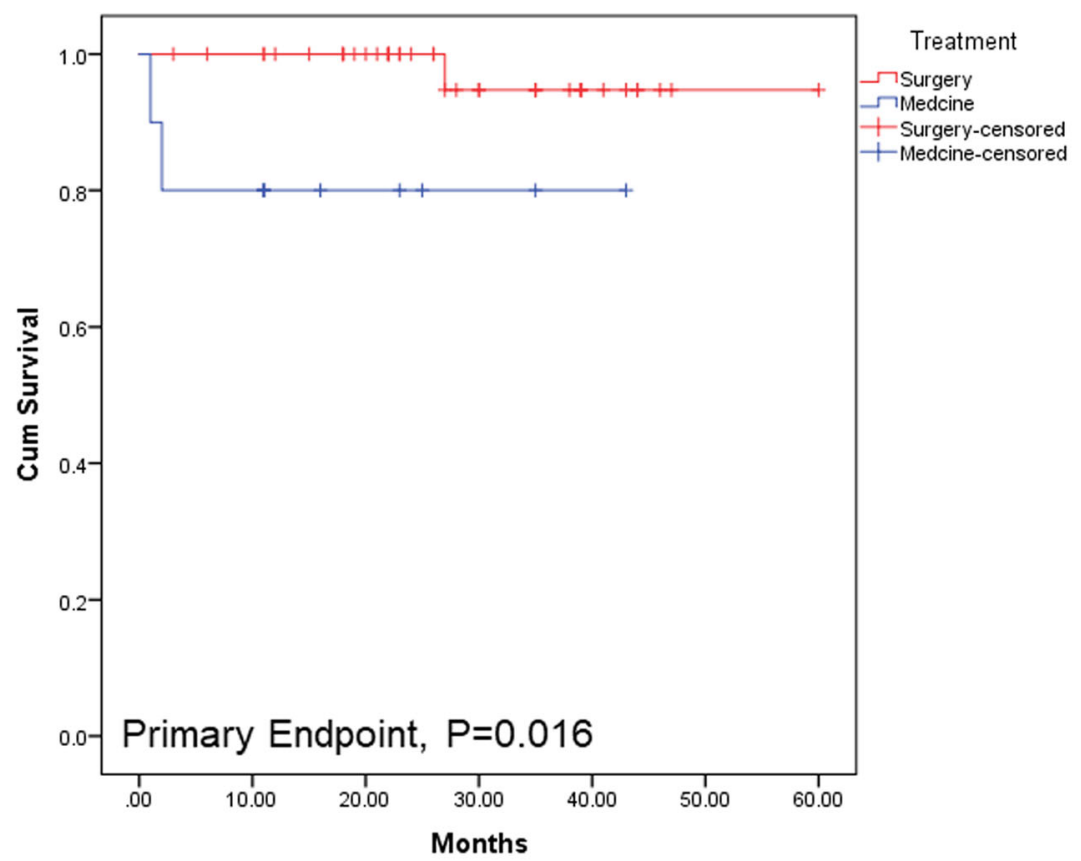

No. at Risk

$\begin{array}{lccccccc}\text { Surgery } & 40 & 39 & 30 & 16 & 10 & 2 & 1 \\ \text { OMT } & 10 & 9 & 5 & 3 & 2 & 1 & 1 \\ & \text { OMT: Optimal medical therapy } & & \end{array}$

Fig. 4 Kaplan-Meier survival curve for type B PAU-IMH patients, surgery vs optimal medical therapy (OMT)

As optimal therapeutic strategy for type B IMH remains debated [14, 15], we compared the outcomes of surgery combined with OMT and OMT only in all patients. As shown in Fig. 3, Kaplan-Meier survival analysis of primary endpoint illustrated no significant difference in both groups $(P=0.192$, Fig. 3$)$. In the $\mathrm{IMH}$ group, there was no difference of prognosis between OMT and surgery treatment (data not shown). We next compared two treatments in type B PAU$\mathrm{IMH}$ patients, and survival analysis showed that surgery improved the prognosis as for primary endpoint
$(P=0.016$, Fig. 4$)$. This result was in consistence with one previous study [11].

\section{Prognosis}

In order to study possible risk factors for type B IMH, we performed multivariable analysis in our cohort. The Cox regression models showed that for all patients in our cohort (Table 3), association with PAU $(\mathrm{HR}=16.68$, 1.960 141.87) and MAD (HR = 1.096, 1.016 1.182) were independent risk factors, whereas surgery was an independent protective factor $(\mathrm{HR}=0.123,0.032 \sim 0.478)$.

Table 3 Cox Regression Analysis of Patients Progression

\begin{tabular}{|c|c|c|c|c|c|c|}
\hline Variable & Progression $(n=16)$ & Regression/Stable $(n=55)$ & $\mathrm{HR}$ & $95 \% \mathrm{Cl}$ & & P \\
\hline Age & $63.3 \pm 11.3$ & $62.3 \pm 10.5$ & 0.993 & 0.929 & 1.062 & 0.842 \\
\hline Surgery & $9(56.3 \%)$ & $37(67.3 \%)$ & 0.123 & 0.032 & 0.478 & 0.002 \\
\hline PAU & 15(93.8\%) & $35(63.6 \%)$ & 16.68 & 1.960 & 141.870 & 0.010 \\
\hline MAD & $44.3 \pm 8.8$ & $40.0 \pm 7.7$ & 1.096 & 1.016 & 1.182 & 0.017 \\
\hline MHT & $13.2 \pm 6.9$ & $12.7 \pm 6.8$ & 0.931 & 0.851 & 1.018 & 0.114 \\
\hline
\end{tabular}

MAD Maximum Aortic Diameter, MHT Maximum Hematoma Thickness 
Table 4 Cox Regression Analysis of PAU-IMH Patients Progression

\begin{tabular}{llllll}
\hline Variable & Progression $(n=15)$ & Regression/Stable $(n=35)$ & HR & $95 \% \mathrm{Cl}$ & $P$ \\
\hline Age & $62.6 \pm 11.3$ & $66.3 \pm 8.1$ & 0.965 & 0.900 & 1.034 \\
Surgery & $9(60.0 \%)$ & $31(88.6 \%)$ & 0.172 & 0.042 & 0.696 \\
MAD & $44.3 \pm 9.1$ & $41.4 \pm 9.0$ & 1.04 & 1.021 & 1.194 \\
MHT & $13.1 \pm 7.1$ & $13.7 \pm 8.0$ & 0.929 & 0.846 & 1.020 \\
\hline
\end{tabular}

MAD Maximum Aortic Diameter, MHT Maximum Hematoma Thickness

Next, we studied type B IMH and PAU-IMH patients separately. The simple type B IMH group contained 21 patients and was too small to bear multivariable analysis. For patients with type B PAU-IMH (Table 4), the model showed that MAD was an independent risk factor $(\mathrm{HR}=$ $1.04,1.021 \sim 1.194)$, while surgical intervention was an independent protective factor $(\mathrm{HR}=0.172,0.042 \sim 0.696)$.

\section{Discussion}

IMH is one type of AAS, which is probably due to vasa vasorum rupture [16], while some studies claimed that IMH should be referred as thrombosed-type aorta dissection $[17,18]$. Although the International Registry of Acute Aortic Dissections (IRAD) illustrated similar prognosis of AD and IMH $[1,19,20]$, some other researchers reported better prognosis and survival rate for IMH when compared with typical AD [1, 21, 22]. Nevertheless, IMH may progress to $\mathrm{AD}$, aneurysm formation, or even death. Thus, it is important to study the prognosis of IMH with different treatment strategies and possible risk factors.

Firstly, we analyzed the impact of treatment on prognosis. Though surgery did not illustrate significant difference in Kaplan-Meier survival analysis for all type B IMH patients, it showed a better prognosis in type B PAU-IMH patients when compared with OMT $(P=$ 0.016). Furthermore, Cox regression analysis showed that surgery presented as an independent protective factor for all type B IMH patients, which might be a confounding bias, considering a large portion of type $\mathrm{B}$ PAU-IMH patients (70.2\%) in this study. Thus, the type B PAU-IMH patients were analyzed separately, and surgery was confirmed as an independent protective factor as adjusted with age, MAD, and maximum hematoma thickness (MHT). Therefore, patients with type B PAUIMH may benefit from surgery. Although ACCF-TAD Guidelines 2010 and JCS-AD Guidelines 2011 did not give recommendation on patients with type B PAUIMH, ESC-AD Guidelines 2014 recommended open surgery or endovascular repair [23]. According to our data, patients with type B PAU-IMH should be referred to surgery more aggressively.

Previously reported risk factors, like PAU, MAD, and MHT [6, 13, 24, 25], were further used to explore prognostic risk factors of type B IMH. For our study, association with PAU was an independent risk factor for type
B IMH patients $(\mathrm{HR}=16.68,1.960 \sim 141.87)$ as well as MAD (HR $=1.096,1.016 \sim 1.182$ ). Furthermore, MAD remained an independent risk factor for type B PAUIMH patients $(H R=1.04,1.021 \sim 1.194)$. However, due to the small sample size, we failed to set up a cut-off value for MAD, which would be addressed in our future study.

\section{Conclusion}

For Chinese type B IMH patients, association with PAU and MAD were independent risk factors. And for type B PAU-IMH patients, MAD was an independent risk factor when surgery was an independent protective factor.

\section{Limitations}

First, our study was a retrospectively observational study with a short-term follow-up, which may lead to potential bias and results should be considered as preliminary. Second, the sample size was rather small due to the low morbidity rate of type B IMH, which hindered further analysis with simple type B IMH patients and MAD.

\section{Abbreviations}

AA: Aortic Aneurysm; AAS: Acute Aortic Syndrome; ACCF-TAD: American College of Cardiology Foundation-Guidelines for the Diagnosis and Management of Patients With Thoracic Aortic Disease; AD: Aortic Dissection; CTA: Computed Tomography Angiography; ESC-AD: European Society of Cardiology-Guidelines for diagnosis and treatment of aortic diseases; IMH: Intramural Hematoma; JCS-AD: Japanese Circulation Society-Guidelines for diagnosis and treatment of Aortic Aneurysm and Aortic Dissection; MAD: Maximum Aortic Diameter; OMT: Optimal Medical Therapy;

PAU: Penetrating Atherosclerosis Ulcer

\section{Acknowledgements}

We thank Ruonan Huang's assistance in data analysis.

\section{Authors' contributions}

$\mathrm{ZL}$ and $\mathrm{CL}$ analyzed and interpreted the patient data and co-wrote the manuscript. RW and CY independently analyzed the CTA data in our study. JZ performed statistical analysis. HP, JT, ZG, YG and NY were responsible for follow-up, data collection and dataset maintenance. GC was the principal investigator and proofread the manuscript and was the major contributor to study concept. All authors read and approved the final manuscript.

\section{Funding}

This work was supported by grants from: 1.The Science and Technology Program of Guangzhou, China (201710010056). 2.The National Natural Science Foundation of China (81670439). 3.The Science and Technology Program of Guangzhou, China (201607010188). The funders had no role in study design, data collection and analysis, decision to publish, or preparation of the manuscript. 


\section{Availability of data and materials}

The datasets used and/or analyzed during the current study are available from the corresponding author on reasonable request.

\section{Ethics approval and consent to participate}

All works were approved by ethic committee of the First Affiliated Hospital, Sun Yat-sen University, with patients' informed consents collected.

\section{Consent for publication}

Consents for publication were obtained from all individuals involved in our study.

\section{Competing interests}

The authors declare that they have no competing interests.

\section{Author details}

'Division of Vascular Surgery, the First Affiliated Hospital of Sun Yat-sen University, Guangzhou, China. ${ }^{2}$ National-Guangdong Joint Engineering Laboratory for Diagnosis and Treatment of Vascular Diseases, the First Affiliated Hospital of Sun Yat-sen University, Guangzhou, China. ${ }^{3}$ Guangdong Provincial Engineering and Technology Center for Diagnosis and Treatment of Vascular Diseases, the First Affiliated Hospital of Sun Yat-sen University, Guangzhou, China. ${ }^{4}$ State Key Laboratory of Ophthalmology, Zhongshan Ophthalmic Center of Sun Yat-Sen University, Guangzhou, China. ${ }^{5}$ Zhongshan School of Medicine, Sun Yat-sen University, Guangzhou, China.

Received: 22 October 2019 Accepted: 6 January 2020

Published online: 23 March 2020

\section{References}

1. Evangelista A, Mukherjee D, Mehta RH, O'Gara PT, Fattori R, Cooper JV, et al. Acute intramural hematoma of the aorta: a mystery in evolution. Circulation. 2005;111(8):1063-70 PubMed PMID: 15710757

2. Song JK. Diagnosis of aortic intramural haematoma. Heart. 2004;90(4):36871.

3. Pelzel JM, Braverman AC, Hirsch AT, Harris KM. International heterogeneity in diagnostic frequency and clinical outcomes of ascending aortic intramural hematoma. J Am Soc Echocardiogr. 2007;20(11):1260-8 PubMed PMID: 17614252.

4. Oderich GS, Karkkainen JM, Reed NR, Tenorio ER, Sandri GA. Penetrating aortic ulcer and intramural hematoma. Cardiovasc Intervent Radiol. 2018; 42(3):321-34 PubMed PMID: 30413917. Epub 2018/11/11

5. KEA, B RL, W DM. Penetrating atherosclerotic ulcers of the descending thoracic aorta evaluation with CT and distinction from aortic dissection. Radiology. 1992;183(3):759-65.

6. Kitai T, Kaji S, Yamamuro A, Tani T, Kinoshita M, Ehara N, et al. Impact of new development of ulcer-like projection on clinical outcomes in patients with type B aortic dissection with closed and thrombosed false lumen. Circulation. 2010;122(11 Suppl):S74-80 PubMed PMID: 20837929.

7. Schoenhoff FS, Zanchin C, Czerny M, Makaloski V, Gahl B, Carrel T, et al. Aorta related and all-cause mortality in patients with aortic intramural Haematoma. Eur J Vasc Endovasc Surg. 2017:54(4):447-53 PubMed PMID: 28802635.

8. Bischoff MS, Meisenbacher K, Wehrmeister M, Bockler D, Kotelis D. Treatment indications for and outcome of endovascular repair of type $B$ intramural aortic hematoma. J Vasc Surg. 2016;64(6):1569-79 e2. PubMed PMID: 27575808

9. Evangelista A, Czerny M, Nienaber C, Schepens M, Rousseau H, Cao P, et al. Interdisciplinary expert consensus on management of type B intramural haematoma and penetrating aortic ulcer. Eur J Cardio-Thoracic Surg. 2015; 47(2):209-17 PubMed PMID: 25385219. Epub 2014/11/12. eng.

10. Erbel R, Aboyans V, Boileau C, Bossone E, Bartolomeo RD, Eggebrecht $H$, et al. 2014 ESC guidelines on the diagnosis and treatment of aortic diseases: document covering acute and chronic aortic diseases of the thoracic and abdominal aorta of the adult. The task force for the diagnosis and treatment of aortic diseases of the European Society of Cardiology (ESC). Eur Heart J. 2014;35(41):2873-926 PubMed PMID: 25173340

11. Ganaha F. Prognosis of aortic intramural hematoma with and without penetrating atherosclerotic ulcer: a clinical and radiological analysis. Circulation. 2002;106(3):342-8.
12. Janosi RA, Gorla R, Tsagakis K, Kahlert P, Horacek M, Bruckschen F, et al. Thoracic endovascular repair of complicated penetrating aortic ulcer: an 11year single-center experience. J Endovasc Ther. 2016;23(1):150-9 PubMed PMID: 26511894. Epub 2015/10/30. eng.

13. Kaji SNK, Akasaka T, Hozumi T, Takagi T, Kawamoto T, Okura H, Shono H, Horibata Y, Honda T, Yoshida K. Prediction of progression or regression of type a aortic intramural hematoma by computed tomography. Circulation. 1999;100(19 Suppl):II281-6.

14. Filippone G, La Barbera G, Valentino F, Ocello S, Guardi D, Ferro G, et al. Conservative Management of Uncomplicated Acute Type B Intramural Hematoma of the aorta not always is the right solution. Ann Vasc Surg. 2019;61:469.e5-469.e11 PubMed PMID: 31394219. Epub 2019/08/09. eng.

15. Chakos A, Twindyawardhani T, Evangelista A, Maldonado G, Piffaretti G, Yan TD, et al. Endovascular versus medical management of type B intramural hematoma: a meta-analysis. Ann Cardiothoracic Surg. 2019:8(4):447-55 PubMed PMID: 31463207. Pubmed Central PMCID: PMC6687962. Epub 2019/08/30.

16. Tsai TT, Nienaber CA, Eagle KA. Acute aortic syndromes. Circulation. 2005; 112(24):3802-13 PubMed PMID: 16344407

17. Kitai T, Kaji S, Yamamuro A, Tani T, Kinoshita M, Ehara N, et al. Detection of intimal defect by 64-row multidetector computed tomography in patients with acute aortic intramural hematoma. Circulation. 2011;124(11 Suppl): S174-8 PubMed PMID: 21911809.

18. Uchida K, Imoto K, Karube N, Minami T, Cho T, Goda M, et al. Intramural haematoma should be referred to as thrombosed-type aortic dissection. Eur J Cardiothoracic Surg. 2013:44(2):366-9 discussion 9. PubMed PMID: 23515169.

19. Harris KM, Braverman AC, Eagle KA, Woznicki EM, Pyeritz RE, Myrmel T, et al. Acute aortic intramural hematoma: an analysis from the international registry of acute aortic dissection. Circulation. 2012;126(11 Suppl 1):S91-6 PubMed PMID: 22965999.

20. Mussa FF, Horton JD, Moridzadeh R, Nicholson J, Trimarchi S, Eagle KA. Acute aortic dissection and intramural hematoma: a systematic review. Jama. 2016;316(7):754-63 PubMed PMID: 27533160.

21. Kang DHSJ, Song MG, Lee IS, Song H, Lee JW, Park SW, Kim YH, Lim TH, Park SJ. Clinical and echocardiographic outcomes of aortic intramural hemorrhage compared with acute aortic dissection. Am J Cardiol. 1998; 81(2):202-6

22. Shimizu HYH, Udagawa H, Watanuki A, Yano K, Ide H, Sudo K, Ishikawa K. Prognosis of aortic intramural hemorrhage compared with classic aortic dissection. Am J Cardiol. 2000;85(6):792-5.

23. Rozado J, Martin M, Pascual I, Hernandez-Vaquero D, Moris C. Comparing American, European and Asian practice guidelines for aortic diseases. J Thorac Dis 2017 May;9(Suppl 6):S551-SS60. PubMed PMID: 28616354. Pubmed Central PMCID: PMC5462729. Epub 2017/06/16.

24. Evangelista A. Prognostic value of clinical and morphologic findings in short-term evolution of aortic intramural haematoma therapeutic implications. Eur Heart J. 2004:25(1):81-7.

25. Sueyoshi E, Onizuka H, Nagayama H, Sakamoto I, Uetani M. Clinical importance of minimal enhancement of type B intramural hematoma of the aorta on computed tomography imaging. J Vasc Surg. 2017;65(1):30-9 PubMed PMID: 27641465.

\section{Publisher's Note}

Springer Nature remains neutral with regard to jurisdictional claims in published maps and institutional affiliations.

Ready to submit your research? Choose BMC and benefit from:

- fast, convenient online submission

- thorough peer review by experienced researchers in your field

- rapid publication on acceptance

- support for research data, including large and complex data types

- gold Open Access which fosters wider collaboration and increased citations

- maximum visibility for your research: over $100 \mathrm{M}$ website views per year

At $\mathrm{BMC}$, research is always in progress.

Learn more biomedcentral.com/submission 